Article

\title{
Power Control of Direct Interconnection Technique for Airborne Wind Energy Systems
}

\author{
Mahdi Ebrahimi Salari *, Joseph Coleman ${ }^{(D)}$ and Daniel Toal(D) \\ Centre for Robotics \& Intelligent Systems, University of Limerick, Limerick V94 T9PX, Ireland; \\ joseph.coleman@ul.ie (J.C.); daniel.toal@ul.ie (D.T.) \\ * Correspondence: mahdi.ebrahimisalari@ul.ie; Tel.: +353-(0)89-254-7896
}

Received: 15 October 2018; Accepted: 11 November 2018; Published: 13 November 2018

\begin{abstract}
In this paper, an offshore airborne wind energy (AWE) farm consisting of three non-reversing pumping mode AWE systems is modelled and simulated. The AWE systems employ permanent magnet synchronous generators (PMSG). A direct interconnection technique is developed and implemented for AWE systems. This method is a new approach invented for interconnecting offshore wind turbines with the least number of required offshore-based power electronic converters. The direct interconnection technique can be beneficial in improving the economy and reliability of marine airborne wind energy systems. The performance and interactions of the directly interconnected generators inside the energy farm internal power grid are investigated. The results of the study conducted in this paper, show the directly interconnected AWE systems can exhibit a poor load balance and significant reactive power exchange which must be addressed. Power control strategies for controlling the active and reactive power of the AWE farm are designed, implemented, and promising results are discussed in this paper.
\end{abstract}

Keywords: airborne wind energy; direct interconnection technique; load sharing control; active power; reactive power exchange; non-reversing pumping mode

\section{Introduction}

Airborne wind energy (AWE) is a promising technology to overcome the technical and the economic constraints of conventional wind turbines for harnessing the stronger and more consistent winds present at higher altitudes. This technology utilises a tethered free-flying kite or glider or flying turbine (in some design approaches) to reach altitudes unreachable for conventional wind turbines. It eliminates the requirement for civil structures such as towers to elevate the system into the wind. Since the first patent of airborne wind energy by Van Gries in 1938 [1], several types of AWE systems have been invented and introduced by researchers and engineers in different universities and companies [1-4]. The non-reversing pumping-mode AWE system employing a kite or a glider for harnessing the wind energy is the focus of this paper [5]. Non-reversing pumping mode AWE systems have been initially developed at the University of Limerick, Ireland [5-7]. In this type of pumping mode AWE system, a kite or glider is tethered to a ground station consisting of a tether drum coupled to a generator and a fractional scale recovery motor. The operation cycle is divided into two phases, a power phase and a recovery phase. During the power phase, the generator is mechanically connected to the tether drum and generates electrical power from the tension profile provided by the flying wing. At the maximum tether length, the operation must be switched to the recovery phase. During the recovery phase, the generator is mechanically bypassed by an overrunning clutch, and the tether drum is reversed by the recovery motor to recover the tether to its initial length [5]. Use of a separate fractional scale motor for the recovery process is the principal deference of the non-reversing pumping mode AWE systems compared to the conventional pumping mode AWE devices where 
they reverse the generator for use as a motor for the recovery process. Reversing the generator in the conventional pumping mode procedure creates difficulty for utility-scale grid interconnection due to the inefficiencies of stopping a large generator and reversing the system as a motor [5]. A variation on the concept of using a separate motor and generator for the recovery phase and power phase are considered by the researchers at TU Delft [8]. The non-reversing pumping mode AWE system is illustrated in Figure 1 (see [5] for greater detail).

Compared to the conventional wind turbines, the need for less mechanical and civil construction has made AWE systems an ideal technology for floating offshore wind energy systems where the size of offshore construction is significantly critical [8-10]. A factor which is more important when reported studies show increasing attention to the offshore wind resources due to higher wind energy availability, less environmental effects and less land limitation in comparison with on-land wind energy systems [11,12]. For instance, the potential of Ireland for the installation of offshore and on-land wind energy systems by 2050 is 30 GW and 11-16 GW, respectively [13], almost double the capacity for offshore wind compared to on-land wind. Furthermore, the Irish maritime area is ten times larger than the country's landmass providing an exceptional land area for the installation of floating wind energy systems [14].

The direct interconnection technique is a new approach to improve the cost and availability of offshore wind energy systems. Pican et al. first introduced the direct interconnection technique (DIT) in 2011 for conventional offshore wind turbines $[15,16]$. In this technique, unlike the conventional approach, all the offshore units are directly interconnected to each other without any power electronic converter. After dispatching the generated power to shore, the farm power is converted in compliance with grid codes by a back to back converter or several paralleled back to back converters. Given that the power electronic converters possess a high rate of failure among the wind turbine sub-assemblies $[17,18]$ and given high expenses of off-shore operations for offshore located back to back converters, this method could provide a significant improvement in the economy and the reliability of the offshore airborne wind energy systems. The direct interconnection technique and the conventional approach for off-shore power integration are illustrated in Figure 2. The first DIT implementation attempt for AWE systems is reported in [5]. In [5], a DIT algorithm is implemented on an offshore AWE farm simulation model proving the initial feasibility of this technique for pumping mode AWE system. The research work of [5] is followed by [19] to investigate the performance of the directly interconnected AWEs under normal and fault conditions. However, there remain many questions about the efficiency and power control of the directly interconnected AWE systems that this current paper answers.

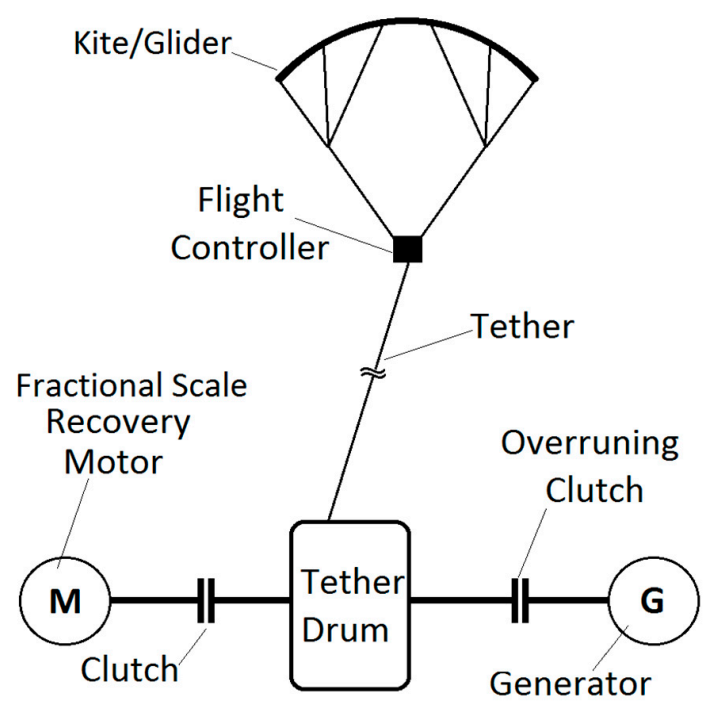

Figure 1. Simplified schematic of a direct drive non-reversing pumping-mode airborne wind energy system. 


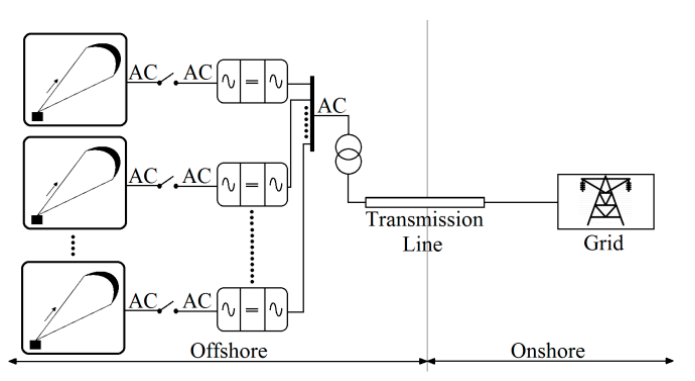

(a)

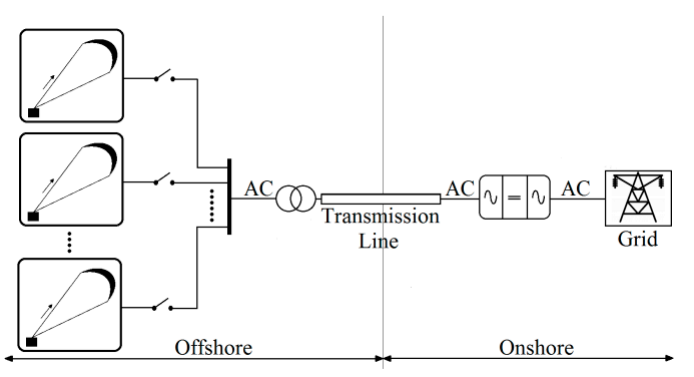

(b)

Figure 2. Conventional approach and direct interconnection technique for an off-shore AWE farm: (a) conventional interconnection method; and (b) direct interconnection technique.

This paper aims to evaluate and optimise the power control of the directly interconnected non-reversing pumping mode AWE systems. Considering AWE systems are directly interconnected to the main bus of the energy farm without any power electronic converter, the power control of the internal grid is an important question as it is a highly dominant factor on the efficiency and performance of the AWE energy farm. In this regard, this research focuses on the power control of the directly interconnected AWE generators inside the internal power grid of an energy farm. Three non-reversing pumping mode AWE systems are modelled and simulated as a minimum viable offshore energy farm. The AWE generators are directly interconnected to the main bus of the energy farm in accordance with the proposed algorithm and by use of automatic frequency and synchronisation controllers. The interaction of the directly interconnected AWE systems inside the internal power grid is studied. Active power, reactive power, power factor, voltage sag and total harmonic distortion (THD) are measured and analysed for the internal power grid of the AWE energy farm. A reactive power compensator (RPC) is designed and implemented to improve the reactive power exchange inside the energy farm internal grid. Also, a load sharing controller (LSC) controls the active power and load balance. Comparing the power generated by the directly interconnected non-reversing pumping mode AWE systems before and after adding the LSC and RPC shows significant improvements in voltage and current oscillation reduction, load balance, and reduction in reactive power of the internal power grid.

\section{Simulation Model}

The power system diagram of the modelled off-shore AWE farm is illustrated in Figure 3. This model is also used in [19] for investigation on the implementation of DIT for AWE systems. For more information regarding the mathematical description of the model see [19]. As can be seen, the farm consists of three non-reversing pumping mode AWE systems. In this model, permanent magnet synchronous generators (PMSG) are used for the electrical power generation. Each AWE system is equipped with an automatic frequency controller (AFC). The AFC in conjunction with the kite flight controller attempts to regulate the incoming torque from the kite to achieve the operating frequency. The AFC is a proportional-integral (PI) controller providing control signals to the flight controller to keep the generator's frequency within the predefined range of operating frequency. The direct interconnection algorithm is demonstrated in Figure 4. After reaching the desired frequency, the automatic synchronisation controller (ASC) starts to work. The ASC compares the frequency, voltage amplitude and voltage angle of the generator and the main bus and once they meet the synchronisation criteria (equal frequencies, equal voltages and equal voltage angles), it interconnects the corresponding AWE unit with the main bus. The ASC comprises three hysteresis controllers (on/off control action). Each hysteresis controller controls one of the synchronisation criteria (i.e., frequency, voltage amplitude and voltage angle). The ASC does not generate the breaker synchronisation command signal unless all three on/off controllers generate an "on" signal at their outputs. 
Before the interconnection, each system is connected to a local resistive dump load, and after the main bus interconnection, the generator is connected to the load along with the other interconnected AWEs. Table 1 shows the specifications of the modelled offshore AWE farm. The nominal frequency of the farm is $18.6 \mathrm{~Hz}$. Controlling the frequency of the farm within an appropriate range around the nominal value is critical for efficient power generation considering the wind speed and the rated frequency and speed of the system components such as the generators. The operation cycle of the AWE systems is $120 \mathrm{~s}$ with a duty cycle of $80 \%$ which means each generation unit operates $96 \mathrm{~s}$ in the power phase of operation and $24 \mathrm{~s}$ in the recovery phase of the operation. To achieve a continuous power at the main bus a $26 \mathrm{~s}$ delay between the operations of the generators is implemented. The simulation is performed by MATLAB/Simulink Simscape Power Systems software, version number 9.2.0.556344 (R2017a).

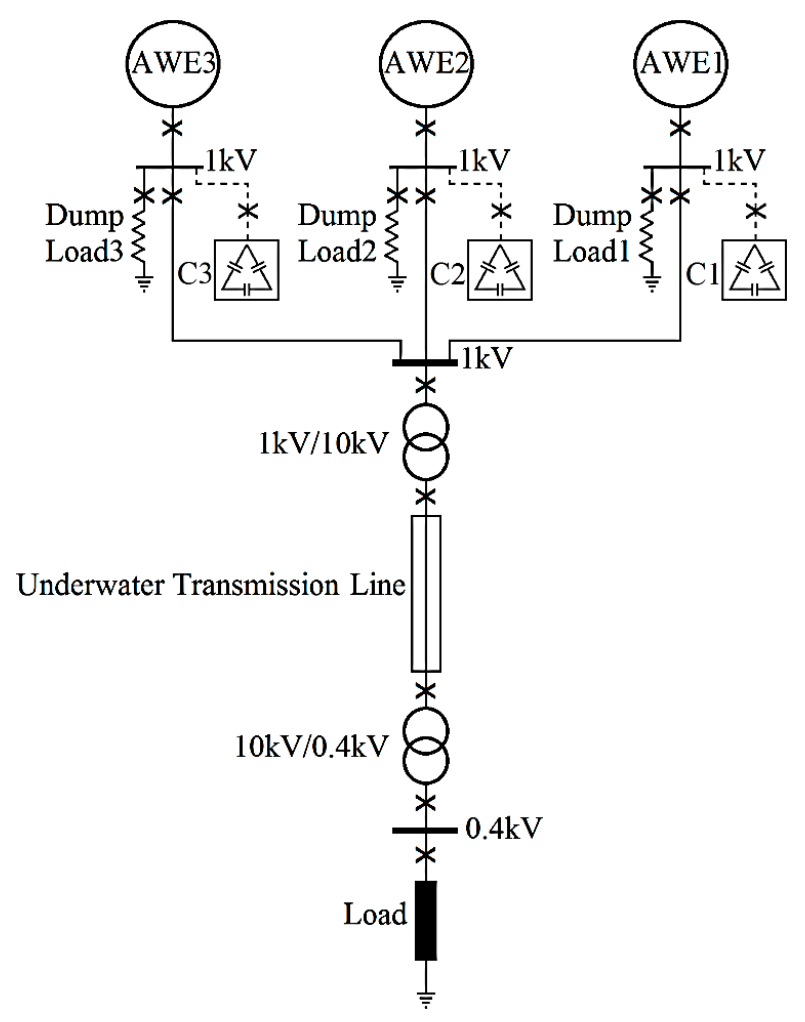

Figure 3. Power system diagram of the simulated offshore non-reversing pumping mode AWE farm.

Table 1. Simulation model specification [19].

\begin{tabular}{lc}
\hline PMSG nominal frequency $(\mathrm{Hz})$ & 18.6 \\
PMSG flux linkage $(\mathrm{Wb})$ & 6.86 \\
PMSG stator resistance $(\mathrm{m} \Omega)$ & 47 \\
PMSG number of pole pairs & 45 \\
Dump loads resistance $(\Omega)$ & 10 \\
Main load resistance $(\Omega)$ & 3.75 \\
AWE period $(\mathrm{s})$ & 120 \\
AWE duty cycle $(\%)$ & 80 \\
AWE cycle phase delay $(\mathrm{s})$ & 26 \\
Transmission line length $(\mathrm{km})$ & 50 \\
Transmission line inductance $(\mathrm{mH} / \mathrm{km})$ & 0.39 \\
Transmission line capacitance $(\mu \mathrm{F} / \mathrm{km})$ & 0.34 \\
\hline
\end{tabular}




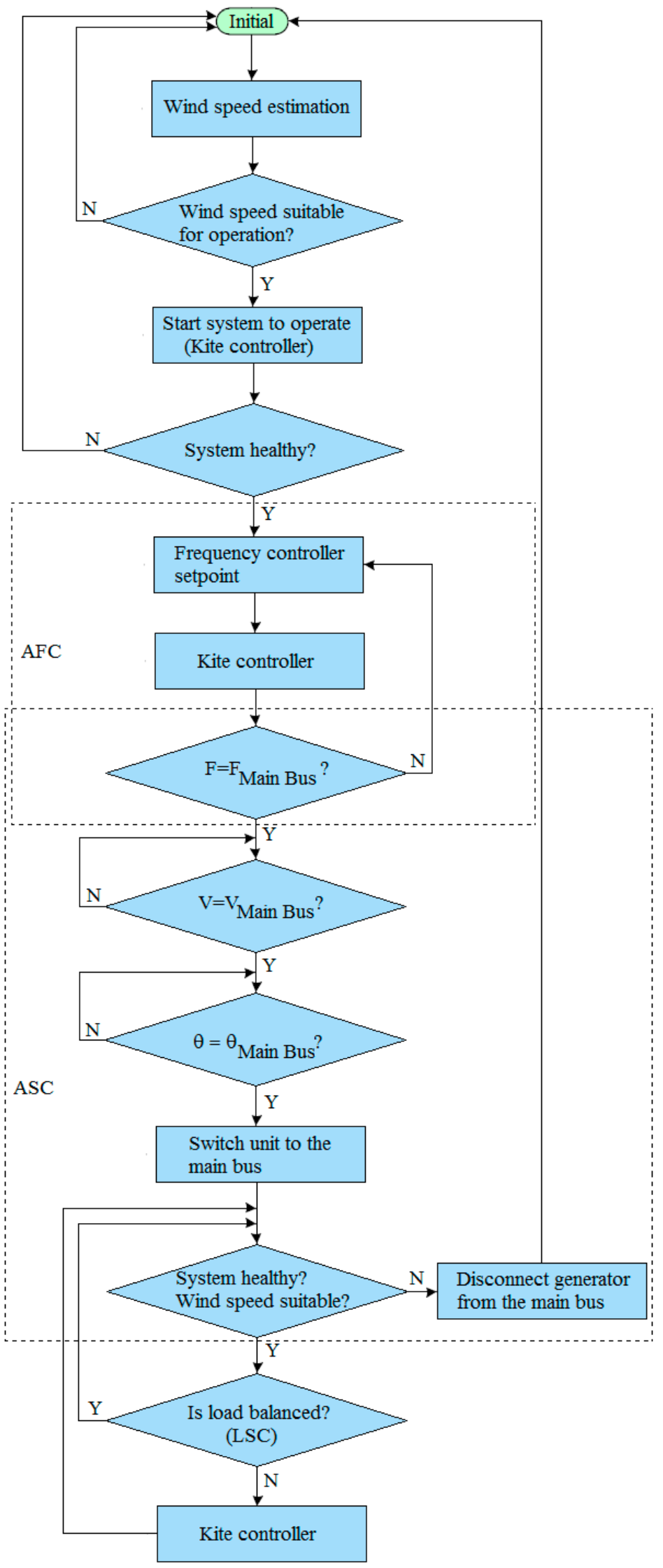

Figure 4. Direct interconnection algorithm. 
Figure 5 shows the torque provided by the kite and the tether to the generator. The torque is modelled as a constant torque with two fluctuating components added to it; a sinusoidal torque representing the periodic manoeuvre of the wing in figure-of-eights inflight and a band-limited white noise torque describing the wind turbulence. Given that the AWE technology is still under development and most AWE projects are in the prototype stage, large datasets of kite test results for modelling the torque from the kite and tether are not available yet. Hence, it is difficult to model the actual shaft torque generated by the kite. However, comparing the torque in Figure 5 with the represented results in [5,20-23], shows the torque in Figure 5 can be considered comparable to the torque in experimental systems.

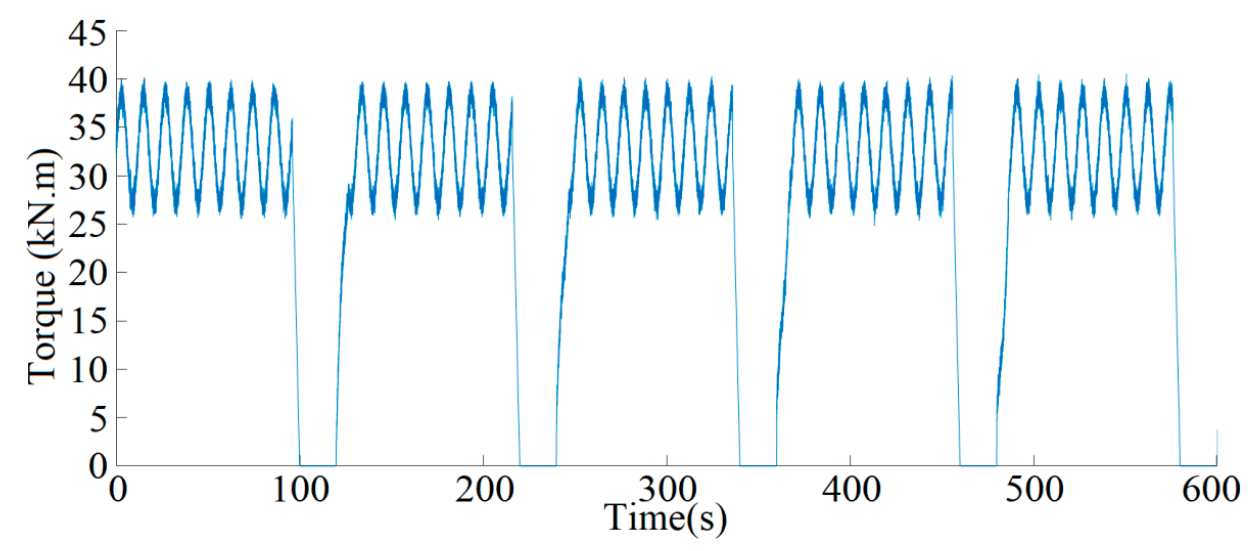

Figure 5. Generator input mechanical torque availability from the kite and tether.

\section{Simulation Results}

The frequency of the generators for $600 \mathrm{~s}$ is demonstrated in Figure 6. AWE1 starts to work at $\mathrm{t}=$ 0 , and AWE2 and AWE3 launch the operation with $26 \mathrm{~s}$ delay at $\mathrm{t}=26 \mathrm{~s}$ and $\mathrm{t}=52 \mathrm{~s}$, respectively. With the operation of each generation unit, automatic frequency controller and automatic synchronisation controller are activated to prepare the corresponding system for the main bus interconnection. As can be seen in Figure 6, AWE2 is integrated into the main bus at $t=51.69 \mathrm{~s}$, and AWE3 joins the main bus at $t=79.45 \mathrm{~s}$. Since the incoming torque from the wing is highly oscillatory, it is not possible to achieve a constant frequency. However, the AFCs can control the steady state frequency within a reasonable range (less than $5 \%$ error) around the operational frequency. After interconnecting all generation units to the main bus, the generators are synchronised, and one AFC can control the main bus frequency. Hence, AFC1 is considered as the main bus frequency controller, and if AFC1 is in the recovery phase or faulty, AFC2 operates as the backup main bus controller.

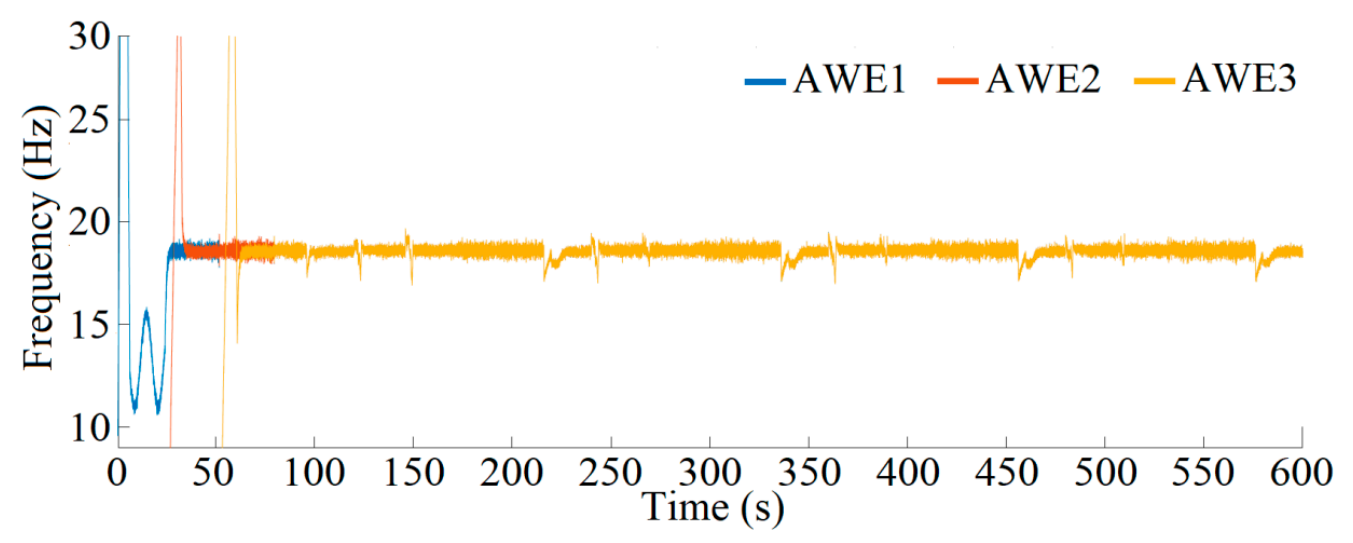

Figure 6. Frequencies of generators. 
The generated power at the main bus is demonstrated in Figure 7. At the start, only AWE1 is interconnected with the main bus and generates $105 \mathrm{~kW}$ electrical power. After the interconnection of AWE2 and AWE3, the electrical power at the main bus increases to $235 \mathrm{~kW}$ and $350 \mathrm{~kW}$ respectively. However, the power generated by each generator is discontinuous. The total power at the main bus is continuous due to the applied time delay between the operation of the AWE systems. Due to the fluctuations in incoming torque from the wing, the active power at the main bus is highly oscillatory. Hence, the utilisation of a power electronic converter before interconnection to the load or the grid is proposed as necessary. According to Figure 8, the RMS value of the phase voltage at the main bus is $564 \mathrm{~V}$, and the peak value of the main bus voltage is $810 \mathrm{~V}$. Figure 9 shows the measured root-mean-square (RMS) current at the terminals of the generators and the main bus. As can be seen, after the interconnection of all generators to the main bus, total current at the main bus changes between $210 \mathrm{~A}$ to $260 \mathrm{~A}$. In Figure 9, the power phase and the recovery phases of the operation are highlighted by green and red colours, respectively.

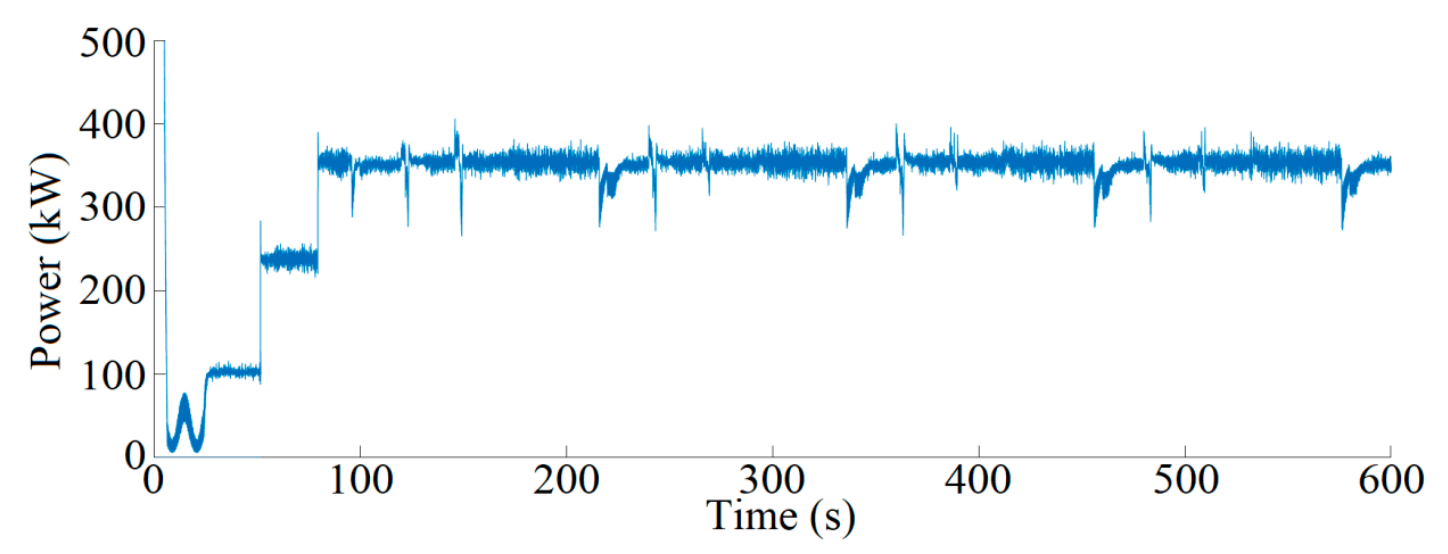

Figure 7. Generated active power of the farm at the main bus.

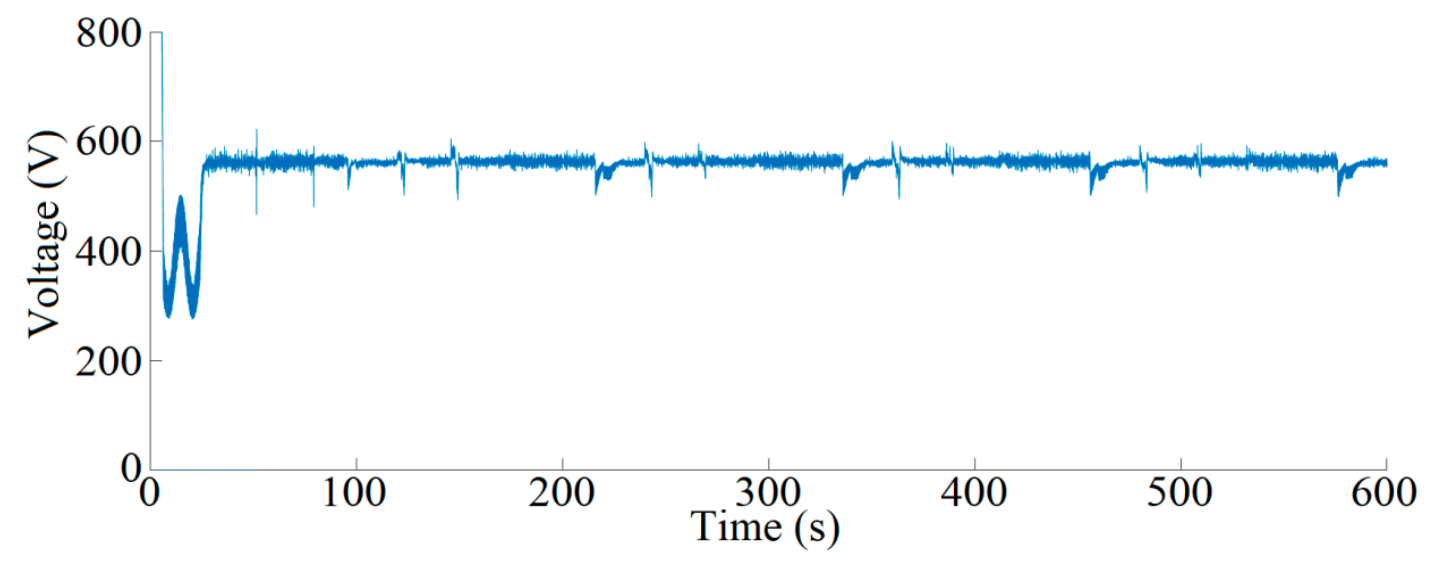

Figure 8. Main bus RMS voltage. 

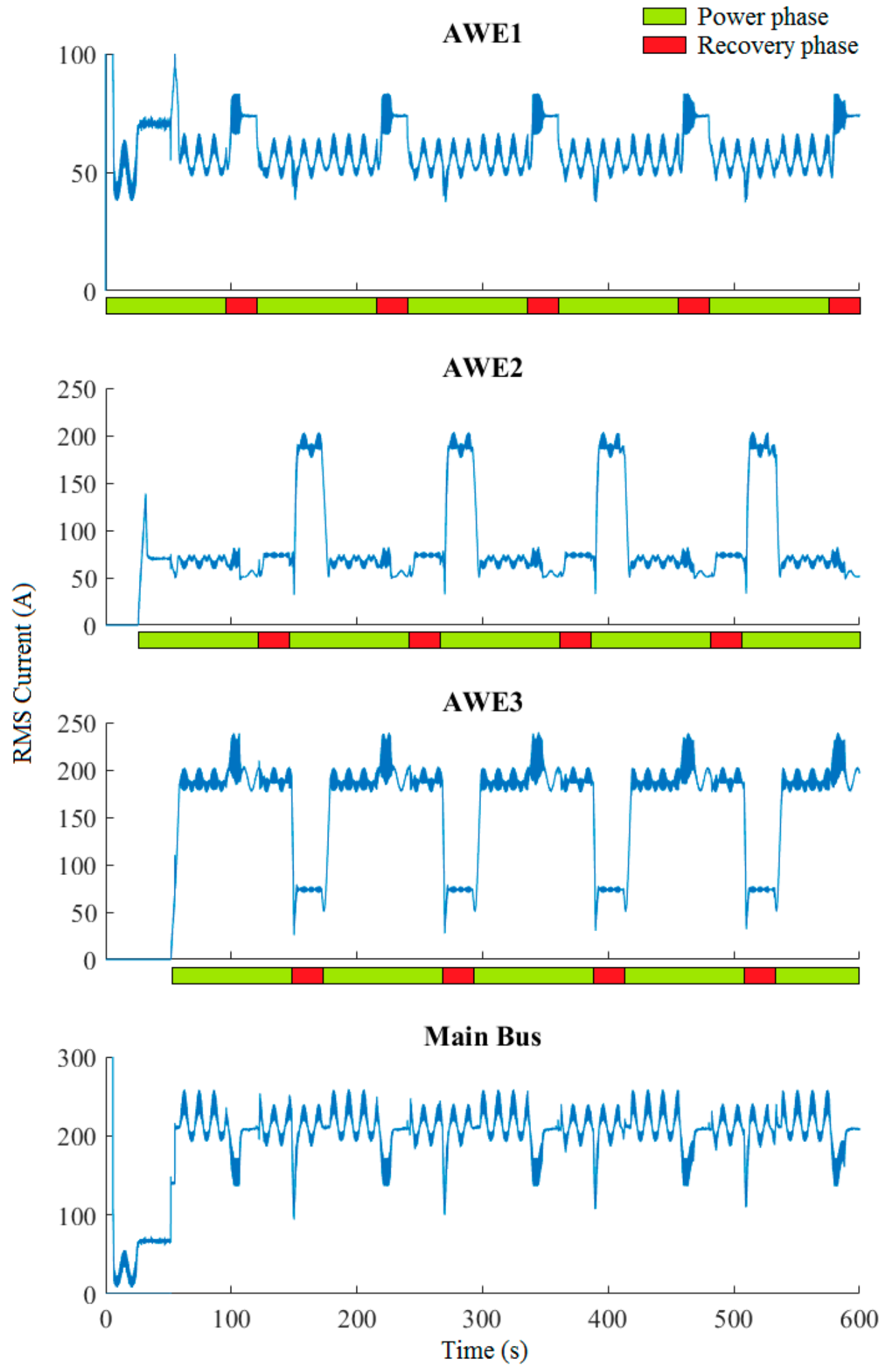

Figure 9. AWE farm currents.

When a directly interconnected AWE unit operates in the recovery phase, it stops power generation and operates as an unloaded synchronous motor. This condition leads to the increase of power generation by other generators to compensate the power shortage, so that power in the main bus is continuous. However, the increase in the power generation is not equal. For instance, between $t$ $=96 \mathrm{~s}$ and $\mathrm{t}=120 \mathrm{~s}$ when AWE1 is in the recovery phase, AWE2 and AWE3 change their generated 
current to around 59 A and 200 A, respectively. Improper power flow and uneven contribution in the generated current can be harmful to the farm power system by increasing the risk of a pole-slipping fault [24-26] and increasing the power losses and current inconsistency due to the circulating current between the generators [27]. A load sharing controller (LSC) is designed and developed to maintain the load balance in the farm power network. The control diagram of the farm is illustrated in Figure 10. The LSC measures and compares the current at the main bus and the generated current by each interconnected generator. If the LSC recognises that a generator is loaded more than other generators it tries to correct the generator contribution by regulating the mechanical torque applied to the generator. The LSC consists of three proportional controllers (P-controllers). Each P-controller controls the power contribution of one AWE unit. Considering the load and the number of power phase and recovery phase AWEs, the LSC estimates each unit's share to set the reference values of P-controllers.

The mechanical torque regulation can be performed by sending a command signal to the kite controller which alters the trajectory and aerodynamic properties of the wing. Figure 11 demonstrates the generators and the bus currents after adding the LSC. As can be seen, the load is divided equally between the generators. For instance, between $t=96 \mathrm{~s}$ and $120 \mathrm{~s}$ when AWE1 is in the recovery phase, the generated currents by AWE2 and AWE3 increase evenly to $110 \mathrm{~A}$. As mentioned, after interconnection of all generators to the main bus, AFC1 operates as the pilot controller to control the farm frequency. In the load sharing strategy, AWE1 is the only generation unit which is permitted to generate slightly more than other generators for the frequency regulation. Comparing Figures 9 and 11 shows the implementation of the LSC causes a significant reduction in the main bus current fluctuations.

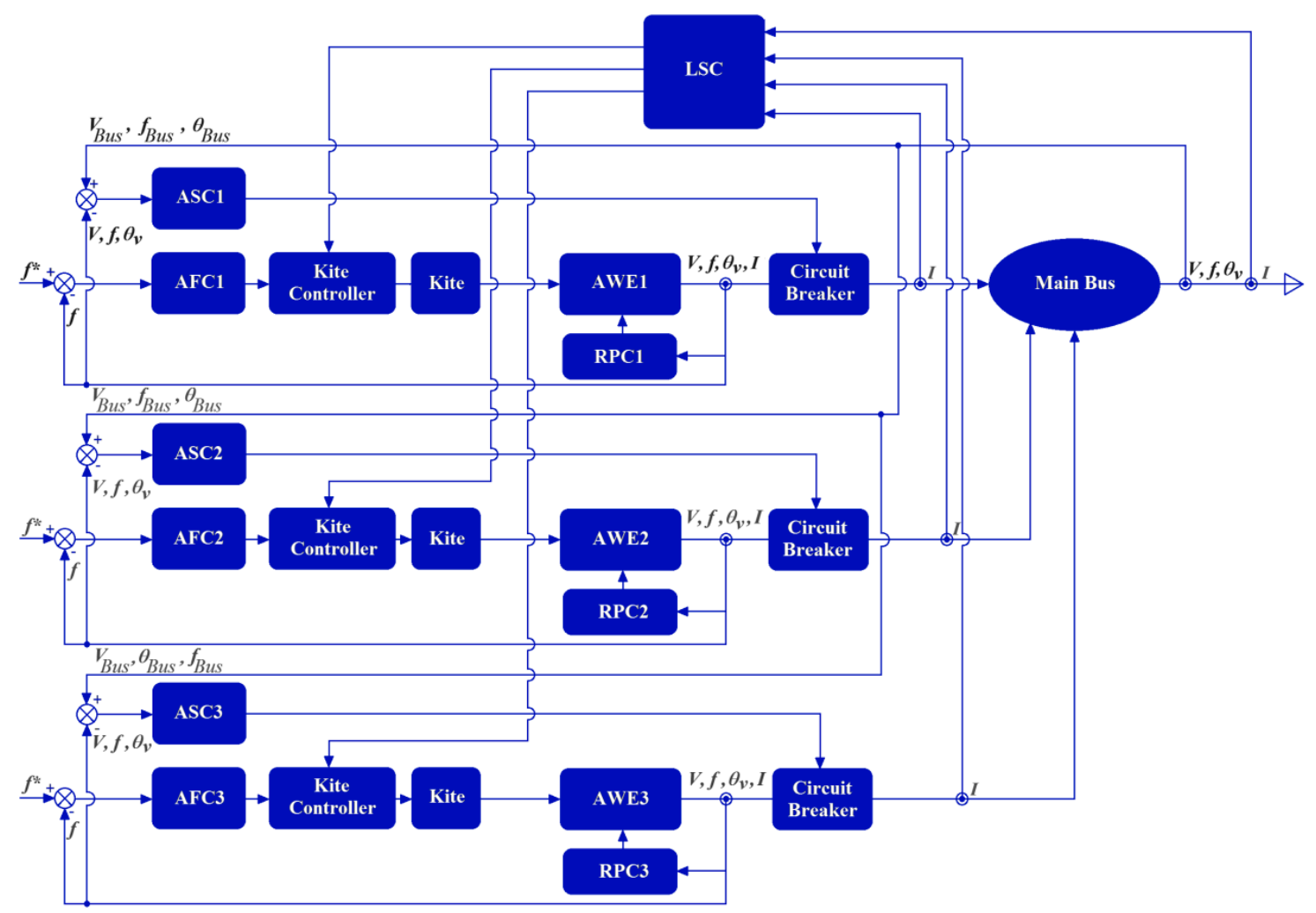

Figure 10. AWE farm control diagram. 

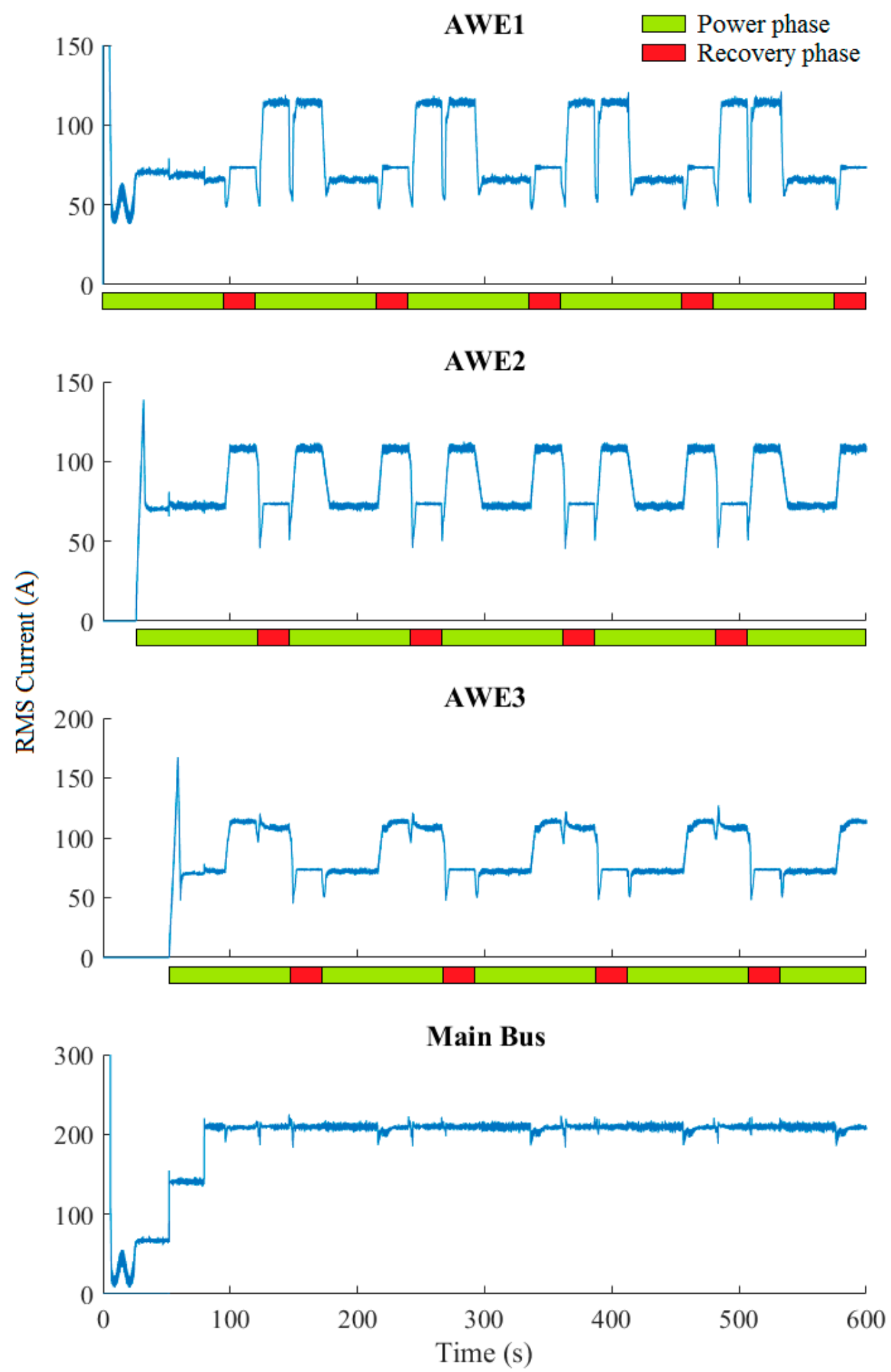

Figure 11. AWE farm currents with LSC active.

In Figures 9 and 11, it can be observed that when a directly interconnected AWE unit is in the recovery phase, the PMSG exchanges about 74 A current with the main bus of the internal power grid. This circulation is due to the reactive power exchange between the idling recovery phase generator and the other generators. To elaborate, during the recovery phase the generator is mechanically decoupled from the kite and the tether drum, but it remains electrically connected to the main bus. In this 
condition, the permanent magnet synchronous generator operates as an unloaded synchronous motor. This unloaded synchronous motor draws a small amount of active power and exchanges a significant amount of reactive power to stay synchronised with the other generators. The reactive power exchange can be seen in Figure 12. As an illustration, between $t=96 \mathrm{~s}$ and $t=120 \mathrm{~s}$, AWE1 is in the recovery phase, and it exchanges $125 \mathrm{kVAR}$ leading reactive power with the main bus. During the same time, it can be seen that the reactive powers of AWE2 and AWE3 are increased to $62 \mathrm{kVAR}$ and $63 \mathrm{kVAR}$ lagging, respectively. This reactive power exchange between the recovery phase AWE and the power phase AWEs reduces the power factor of the generators. Also, it results in increased power losses by increasing the current flow through the internal power grid equipment such as transmission lines, generators, transformers and circuit breakers. A reactive power controller (RPC) is developed and implemented for each AWE unit. The RPC consists of a variable capacitor bank parallel to the terminals of the generator, and a controller tracking the reactive power exchanges. If an RPC detects any lagging reactive power at the output of an AWE unit, it switches the appropriate number of capacitors to the generator terminal to compensate the lagging reactive power. In Figure 3, the capacitor banks are specified by $\mathrm{C} 1, \mathrm{C} 2$, and C3 for AWE1, AWE2, and AWE3 respectively. After adding RPC to each AWE unit, the reactive power exchange is limited to the synchronous machine and the shunt capacitor banks connected to the machine terminals, and it is not exchanged between the AWE units through the farm internal power grid anymore.

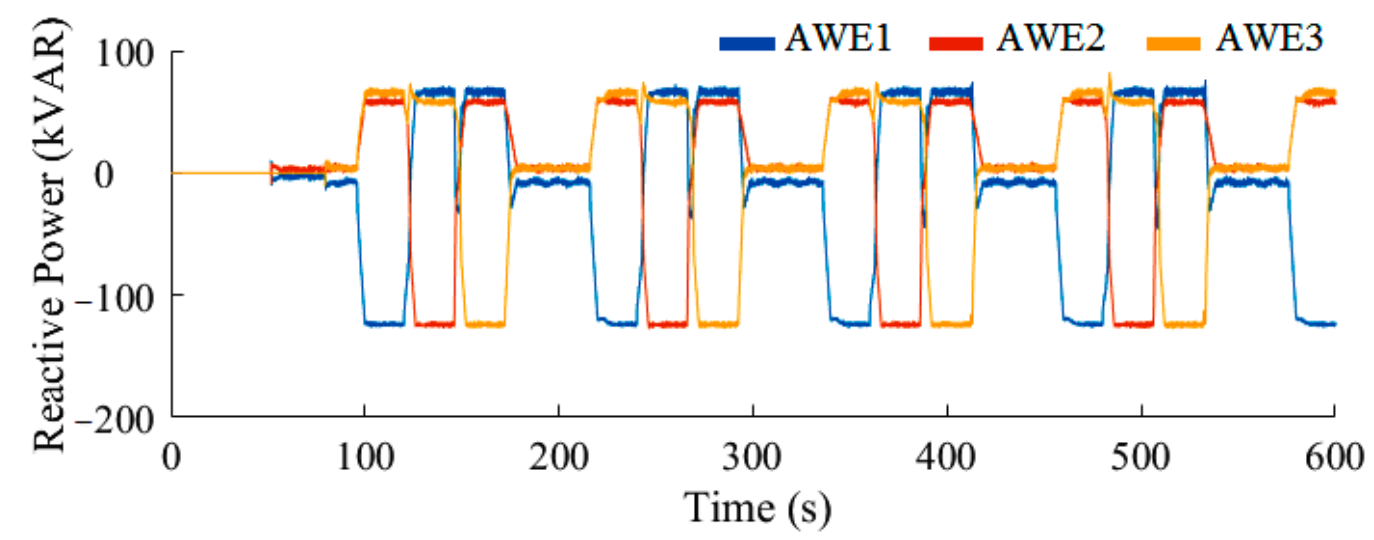

Figure 12. AWE farm reactive power exchange without RPC active.

Figure 13 demonstrates the reactive power exchange inside the energy farm internal power grid after adding the RPCs. As can be seen, when an AWE unit is in the recovery phase, the amount of exchanged reactive power with other generators is decreased by $95 \%$. For instance, when AWE1 is in the recovery phase (between $t=96$ and 120) the exchanged reactive power with the AWE2 and AWE3 (except during the transient time of the phase transmission) is $6.5 \mathrm{kVAR}$ approximately. During this period, the lagging reactive power is compensated by RPC2 and RPC3. Similarly, when AWE2 and AWE3 operate in the recovery phase, the lagging reactive power is compensated by RPC1 and RPC 3 for the AWE2 recovery phase, and RPC1 and RPC2 for the AWE3 recovery phase, and the circulating reactive power is decreased significantly. This reactive power compensation can improve the capacity of the AWE energy farm for providing more active power to the load/grid by reducing the circulating current inside the internal power grid. Figure 14 shows the farm currents after the utilisation of RPCs. Compared to Figure 11, the current exchange of the recovery phase AWE with the main bus has decreased from $74 \mathrm{~A}$ to $3.5 \mathrm{~A}$, which is a $95.27 \%$ reduction in the circulating current. 


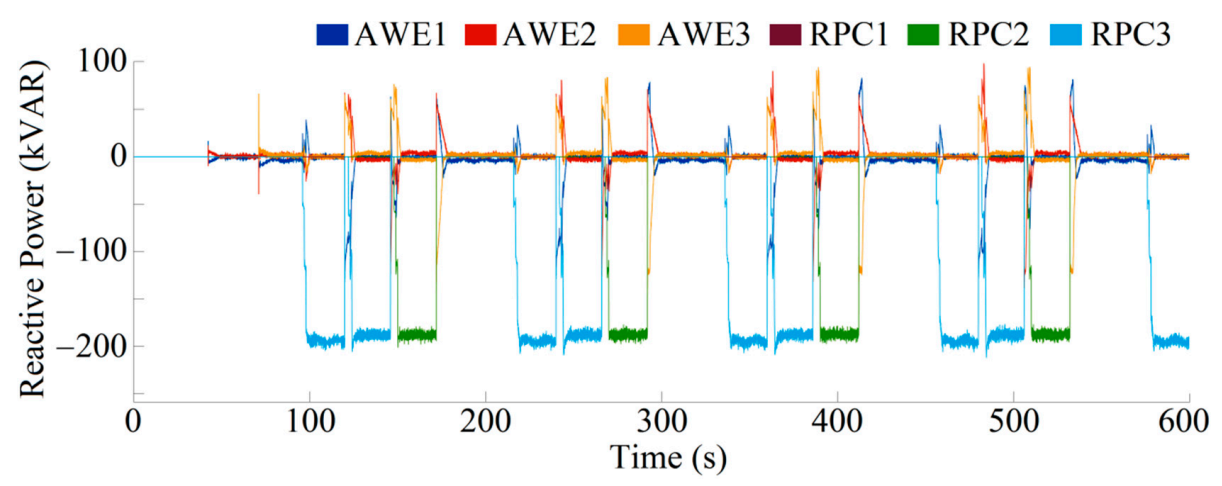

Figure 13. AWE farm reactive power exchange with RPC active.

Table 2 compares the average power factors of the AWE units before and after the use of RPCs. In this table, "+" indicates a lagging power factor, and "-" represents a leading power factor. A significant improvement in the power factor can be seen by adding RPCs to the farm. For instance, without RPC, the average power factor of the AWE1 during the recovery phase is 0.01 leading while, by RPC, it is corrected to 0.83 lagging. The power factor improvement can be observed for AWE2 and AWE3 as well. The average power factor of AWE2 and AWE3 over the recovery phase is improved from the weak value of 0.01 leading to 0.70 and 0.72 lagging, respectively. Additionally, the average power factor of the power phase AWEs when one AWE unit operates in the recovery phase is improved to the value of 1 .

Figure 15 shows a voltage sag investigation at the main bus of the energy farm. According to the IEEE 1159 standard, voltage sag is a voltage drop to between 10 to $90 \%$ of the nominal voltage lasting more than half of a cycle and less than one minute [28]. Voltage sag can happen as a result of events such as short circuit fault, the start of induction motors and variations in the load [28]. This type of voltage drop can be a critical problem since it can affect the proper operation of the power system causing damage to the power grid and end-user equipment [28]. Furthermore, it may lead to unwanted protection system trips [28]. In DIT, the transition of an interconnected generator from the power to recovery phase and vice versa cases, variations in the mechanical torque and speed of the tethered wing, and the switching operation of the capacitor banks (after adding RPCs) can potentially cause voltage sag in the energy farm power network. The represented voltage sag analysis in Figure 15 compares voltage sag events with and without the LSC and RPC for $600 \mathrm{~s}$ of the simulation at the main bus of the internal power grid. In this figure, the term ' $\mathrm{N}$ ' represents how many times each voltage sag event has happened. Figure 15a shows that without the LSC and RPCs, a total of 22 voltage sag events have occurred. Among them, the most intensive is the sag to $45 \%$ with the duration of 119.18 cycles and a repetition of four times. The longest voltage sag is 238.36 cycles with a magnitude of $65 \%$ and repetition five times. The sag to $89 \%$ is the most frequent voltage sag event with 13 repetitions and duration of 106.14 cycles. Figure $15 \mathrm{~b}$ represents voltage sag analysis after adding the LSC and RPCs. The number of voltage sag events is reduced to 11; a $50 \%$ improvement in the number of voltage sag events. In Figure $15 \mathrm{~b}$ the most intensive event is a sag to $85 \%$ with a duration of 1.30 cycles, compared to the most intensive sag before adding LSC and RPCs (Figure 15a) $88.88 \%$ and $98.90 \%$ improvement in the magnitude and duration is achieved, respectively. Additionally, Figure 15b shows that the longest sag with LSC and RPCs is 55.68 cycles while without the LSC and RPCs it was 238.36 cycles, i.e., a $76.64 \%$ improvement. 

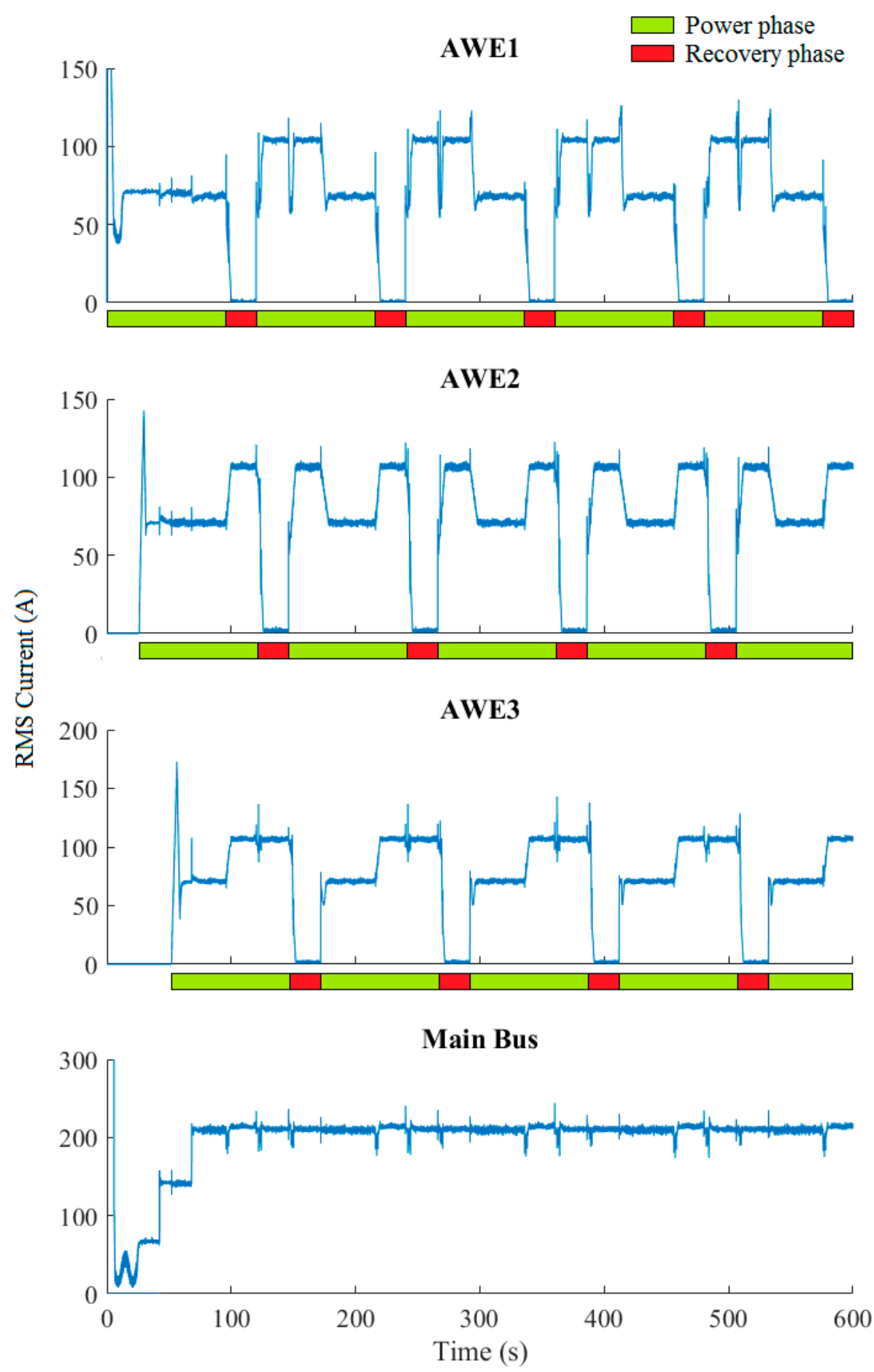

Figure 14. AWE farm currents after using RPCs active.

Table 2. Average power factors of AWE units with and without RPC.

\begin{tabular}{lccccccc}
\hline \multirow{2}{*}{ Power Phase } & \multirow{2}{*}{ Recovery Phase } & \multicolumn{2}{c}{ AWE1 } & \multicolumn{2}{c}{ AWE2 } & \multicolumn{2}{c}{ AWE3 } \\
\cline { 3 - 8 } & & Without RPC & With RPC & Without RPC & With RPC & Without RPC & With RPC \\
\hline AWE2, AWE3 & AWE1 & -0.01 & +0.83 & +0.95 & +1 & +0.94 & +1 \\
AWE1, AWE3 & AWE2 & +0.94 & +1 & -0.01 & +0.70 & +0.95 & +1 \\
AWE2, AWE1 & AWE3 & +0.94 & +1 & +0.95 & +1 & -0.01 & 0.72 \\
\hline
\end{tabular}


Figure 16 investigates the total harmonic distortion (THD) of the main bus current before and after implementation of the LSC and RPCs. THD is an index showing the signal distortion due to harmonics. Current THD can be determined by Equation (1) as the ratio of the cumulative harmonics to the fundamental frequency of the current [29].

$$
\operatorname{THD}_{I}(\%)=\left(\sqrt{\sum_{i=2}^{\infty} I_{i}}\right) / I_{1} \times 100
$$

where $I i$ is the RMS value of $i$-th order harmonic and $I_{1}$ is the RMS value of the fundamental frequency of the current.

In Figure 16a it can be observed that without the implementation of the LSC and RPCs the main bus current THD can rise to $65.3 \%$. Figure $16 \mathrm{~b}$ shows the maximum current $T H D$ is decreased to $27.94 \%$ by the use of LSC and RPCs which is a $57.21 \%$ decrease in current THD at the main bus. This significant improvement in the THD of the power generated by the directly interconnected generators is highly effective in the reduction of core losses in power transformers and electrical machines lowering the thermal stress on the farm internal power grid equipment [30]. However, this THD is still unsuitable for electric power consumers as according to the IEEE Std. 519-1992 the current THD at the point of common coupling (PCC) with the infinite power grid must be below 5\% [30]. Hence, THD must be reduced to less than $5 \%$ for the grid interconnection by the implementation of one or several paralleled back to back power electronic converters in the onshore substation before integration with the infinite power grid. As mentioned, such converters are, in any case, required for frequency and voltage compliance.

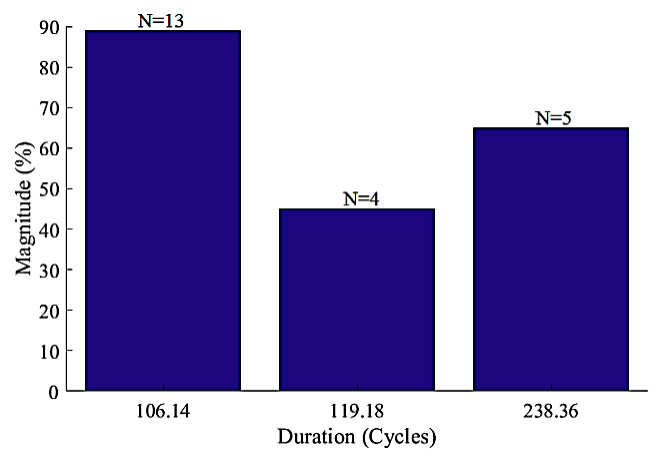

(a)

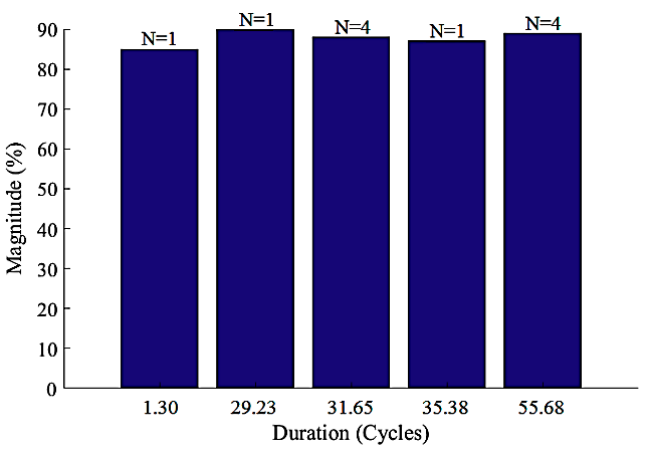

(b)

Figure 15. Voltage sag events at the main bus: (a) Voltage sag events without LSC and RPCs; and (b) voltage sag events with the LSC and RPCs active.

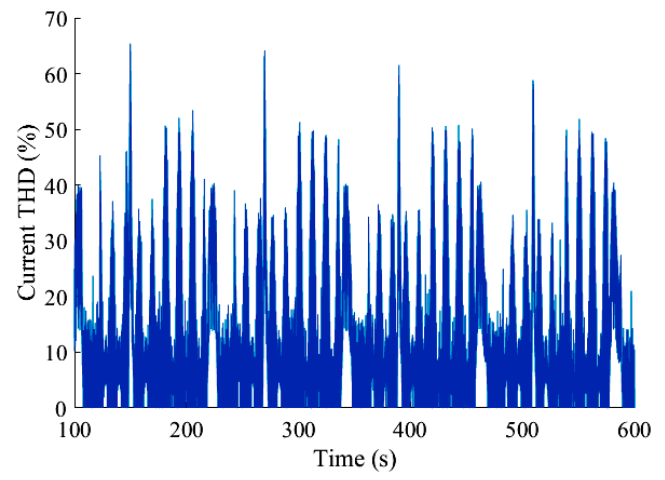

(a)

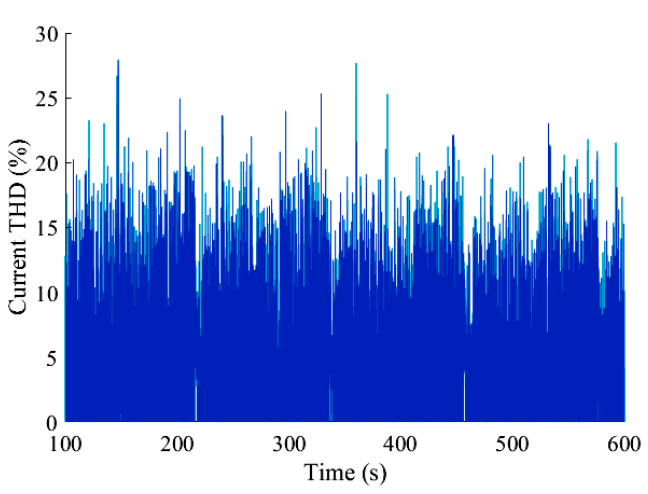

(b)

Figure 16. Current THD at the main bus: (a) Current THD without LSC and RPCs; and (b) current THD with LSC and RPCs active. 


\section{Discussion and Conclusions}

The direct interconnection technique is a novel approach for the integration of offshore airborne wind energy systems. In this technique, transferring the power electronic converters from the offshore site to shore can significantly improve the economy and reliability of the offshore AWE farms. However, this paper shows that the elimination of the power electronic converters from the terminals of the generators and the integration of AWE generators directly to the offshore main bus can lead to less controllability and, hence, reduced power factor, significant reactive power exchange between the generators, poor load balance, and wild fluctuations in voltage and current. Accordingly, a DIT internal power grid needs power controllers to improve the efficiency and reliability of generated power. It is shown that without controlling the contribution of each generator in the active power generation, the load is divided unequally between the generators. This uneven load sharing loads some generators more than other generators and can be harmful to the overloaded generators and the internal power grid equipment, such as transformers, breakers, and capacitors.

The reactive power exchange between the directly interconnected airborne wind energy systems has been analysed. It is shown that when an AWE unit operates in the recovery phase, it exchanges a considerable amount of reactive power with other interconnected machines to stay synchronised with them. This reactive power exchange causes a significant circulating current within the AWE energy farm leading to a reduced active power capacity of the energy farm and increased power losses of the internal power grid equipment such as transmission lines and transformers.

A load sharing controller is designed and implemented to control the load balance inside the farm. The LSC measures and compares the generated current of each generator and the total bus current to maintain load balance. Comparing the generated current before and after adding LSC shows a significant improvement in the farm load flow. With LSC included, the generators give an equal contribution to the load demand, and even when a unit is in recovery the generated power from the other generators increases equally in response to the power shortage.

Reactive power controllers (RPC) are developed and implemented for each AWE unit to control the reactive power exchange. The reactive power exchange before and after adding RPCs is compared. The simulation results show that the use of RPCs considerably decreases the reactive power exchange between the directly interconnected AWE systems. Additionally, it causes a significant power factor improvement and $95 \%$ reduction in the amount of circulating current inside the internal power grid. Voltage sag and THD have been investigated. It is shown that by the appropriate control of active and reactive power for directly interconnected pumping mode AWE systems it is possible to make a reduction of $57.21 \%$ and $50 \%$ in current $T H D$ and the number of voltage sag events, respectively. Similarly, considerable improvements in the magnitude and duration of voltage sag events are achieved by the implementation of the LSC and RPCs.

Controlling active and reactive power is a critical factor for improving the reliability and efficiency of the directly interconnected airborne wind energy systems. This research has achieved a notable improvement in the quality of power inside the internal power grid for the directly interconnected AWE systems by the design and implementation of appropriate active and reactive power controllers. However, due to the variable mechanical power input from the AWE kites, this power still requires on-shore power electronic converters (back to back converters) prior to integration with the infinite power grid or load.

This paper focuses on the ground station of AWE systems and assumes that the AWE's kite is ideally controllable for torque regulation. Due to the lack of experimental test results, it is not possible to understand how far the kite and flight controller can collaborate with the controllers of the direct interconnection technique. In future work, this must be investigated by adding an aerodynamic model of kite including feasible flight controllers to the current AWE farm model and the experimental testing of DIT on real AWE devices. Moreover, in the future this research work plans to study the integration of the directly interconnected pumping mode AWE systems to the infinite power grid via back-to-back power electronic converters. 
Author Contributions: M.E.S. carried out the reported research work, writing the paper and revisions. J.C. and D.T. supervised the research work, revisions, and language editing. The content of this paper is discussed by the authors, and they all contributed to the final manuscript.

Funding: This work is supported by the project AWESCO (H2020-ITN-642682) funded by the European Union's Horizon 2020 research and innovation programme under the Marie Skłodowska-Curie grant agreement No. 642682. This publication has emanated from research supported in part by a research grant from Science Foundation Ireland (SFI) under MaREI Grant No. 12/RC/2302.

Conflicts of Interest: The authors declare that the publication this article has no conflict of interest.

\section{References}

1. Mendonça, A.K.S.; Vaz, C.R.; Lezana, A.G.R.; Anacleto, C.A.; Paladini, E.P. Comparing Patent and Scientific Literature in Airborne Wind Energy. Sustainability 2017, 9, 915. [CrossRef]

2. Cherubini, A.; Papini, A.; Vertechy, R.; Fontana, M. Airborne wind energy systems: A review of the technologies. Renew. Sustain. Energy Rev. 2015, 51, 1461-1476. [CrossRef]

3. Salari, M.E.; Coleman, J.; Toal, D. Airborne wind energy-A review. In 3rd International Congress on Energy Efficiency and Energy Related Materials (ENEFM2015); Oral, A.Y., Oral, B., Banu, Z., Eds.; Springer International Publishing: Berlin/Heidelberg, Germany, 2016; pp. 81-92. ISBN 978-3-319-45677-5.

4. Diehl, M. Airborne Wind Energy: Basic Concepts and Physical Foundations. In Airborne Wind Energy; Ahrens, U., Diehl, M., Schmehl, R., Eds.; Springer: Berlin/Heidelberg, Germany, 2013; pp. 3-22. ISBN 978-3-642-39965-7.

5. Coleman, J.; Ahmad, H.; Pican, E.; Toal, D. Modeling of a synchronous offshore pumping mode airborne wind energy farm. Energy 2014, 71, 569-578. [CrossRef]

6. Coleman, J.; Pican, E.; Ahmad, H.; Toal, D. Experimental Developments of a Pumping Mode Kite Power Demonstrator with Non-reversing Generator. In Proceedings of the Airborne Wind Energy Conference (AWEC2013), Berlin, Germany, 10-11 September 2013.

7. Coleman, J.; Ahmad, H.; Toal, D. Development and Testing of a Control System for the Automatic Flight of Tethered Parafoils. J. Field Robot. 2017, 34, 519-538. [CrossRef]

8. Fechner, U.; Schmehl, R. Model-based efficiency analysis of wind power conversion by a pumping kite power system. In Airborne Wind Energy; Ahrens, U., Diehl, M., Schmehl, R., Eds.; Springer: Berlin/Heidelberg, Germany, 2013; pp. 249-269. ISBN 978-3-642-39965-7.

9. Archer, C.L.; Monache, L.D.; Rife, D.L. Airborne wind energy: Optimal locations and variability. Renew. Energy 2014, 64, 180-186. [CrossRef]

10. Heptonstall, P.; Gross, R.; Greenacre, P.; Cockerill, T. The cost of offshore wind: Understanding the past and projecting the future. Energy Policy 2012, 41, 815-821. [CrossRef]

11. Global Wind Energy Council. Wind Global Wind Report-Annual Market Update 2017. Available online: http:/ / files.gwec.net/ files/GWR2017.pdf (accessed on 1 November 2018).

12. Colmenar-Santos, A.; Perera-Perez, J.; Borge-Diez, D.; Palacio-Rodríguez, C. Offshore wind energy: A review of the current status, challenges and future development in Spain. Renew. Sustain. Energy Rev. 2016, 64, 1-18. [CrossRef]

13. SEAI. Wind Energy Road Map-Introduction to the Wind Energy Roadmap to 2050. Available online: https: //www.seai.ie/resources/publications/Wind_Energy_Roadmap_2011-2050.pdf (accessed on 1 November 2018).

14. Ireland Department of Communication, Energy and Natural Resources, Ireland's Transition to a Low Carbon Energy Future 2015-2030. Available online: https: / www.dccae.gov.ie/en-ie/energy / publications / Documents/2/Energy\%20White\%20Paper\%20-\%20Dec\%202015.pdf (accessed on 1 November 2018).

15. Pican, E.; Omerdic, E.; Toal, D.; Leahy, M. Analysis of parallel connected synchronous generators in a novel offshore wind farm model. Energy 2011, 36, 6387-6397. [CrossRef]

16. Toal, D.; Pican, E.; Leahy, M. Improvements in and Relating to Wind Farms. European Patent EP2647098, 2 December 2010.

17. Spinato, F.; Tavner, P.J.; Van Bussel, G.J.W.; Koutoulakos, E. Reliability of wind turbine subassemblies. IET Renew. Power Gener. 2009, 3, 1-15. [CrossRef]

18. Zhao, Y.; Li, D.; Dong, A.; Kang, D.; Lv, Q.; Shang, L. Fault Prediction and Diagnosis of Wind Turbine Generators Using SCADA Data. Energies 2017, 10, 1210. [CrossRef] 
19. Salari, E.M.; Coleman, J.; Toal, D. Analysis of Direct Interconnection Technique for Offshore Airborne Wind Energy Systems under Normal and Fault Conditions. Renew. Energy 2019, 131, 284-296. [CrossRef]

20. Van der Vlugt, R.; Peschel, J.; Schmehl, R. Design and experimental characterization of a pumping kite power system. In Airborne Wind Energy; Ahrens, U., Diehl, M., Schmehl, R., Eds.; Springer: Berlin/Heidelberg, Germany, 2013; pp. 403-425. ISBN 978-3-642-39965-7.

21. Bormann, A.; Maximilian, R.; Kövesdi, P.; Gebhardt, C.; Skutnik, S. Development of a three-line ground-actuated airborne wind energy converter. In Airborne Wind Energy; Ahrens, U., Diehl, M., Schmehl, R., Eds.; Springer: Berlin/Heidelberg, Germany, 2013; pp. 427-436. ISBN 978-3-642-39965-7.

22. Fritz, F. Application of an automated kite system for ship propulsion and power generation. In Airborne Wind Energy; Ahrens, U., Diehl, M., Schmehl, R., Eds.; Springer: Berlin/Heidelberg, Germany, 2013; pp. 359-372. ISBN 978-3-642-39965-7.

23. Ruiterkamp, R.; Sieberling, S. Description and preliminary test results of a six degrees of freedom rigid wing pumping system. In Airborne Wind Energy; Ahrens, U., Diehl, M., Schmehl, R., Eds.; Springer: Berlin/Heidelberg, Germany, 2013; pp. 443-458. ISBN 978-3-642-39965-7.

24. Klempner, G.; Kerszenbaum, I. Operation and Maintenance of Large Turbo Generators; John Wiley \& Sons: Hoboken, NJ, USA, 2004; pp. 27-32. ISBN 0-471-61447-5.

25. Berdy, J. Out of Step Protection for Generators, GE Publication No. GER-3179. Available online: https: / / store.gegridsolutions.com/FAQ/Documents/CEB/GER-3179.pdf (accessed on 2 October 2018).

26. Bai, W.; Lee, D.; Lee, K.Y. Stochastic Dynamic AC Optimal Power Flow Based on a Multivariate Short-Term Wind Power Scenario Forecasting Model. Energies 2017, 10, 2138. [CrossRef]

27. Laughton, M.A.; Warne, D.J. Electrical Engineer's Reference Book; Elsevier: London, UK, 2003; ISBN 9780750646376.

28. IEEE Standards Board. 1159-1995-IEEE Recommended Practice for Monitoring Electric Power Quality; The Institute of Electrical and Electronics Engineers Inc.: New York, NY, USA, 1995.

29. Blooming, T.M.; Carnovale, D.J. Application of IEEE STD 519-1992 Harmonic Limits. In Proceedings of the Pulp and Paper Industry Technical Conference, Appleton, WI, USA, 18-23 June 2006. [CrossRef]

30. Ellis, R.G. Power Systems Harmonics: A Reference Guide to Causes, Effects and Corrective Measures. An Allen-Bradley Series of Issues and Answers, Rockwell International Corporation. Available online: http:/ / literature.rockwellautomation.com/idc/groups/literature/documents/wp/mvb-wp011_ -en-p.pdf (accessed on 2 October 2018). 